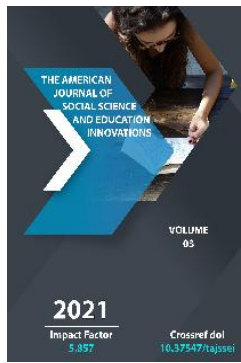

\title{
Teaching Foreign Languages Using Reflexive Methods
}

Nigora Khaydarova

Teacherat The Department Of "Uzbek And Foreign Languages" Of Fergana Medical Institute of Public Health, Tashkent, Uzbekistan

\section{ABSTRACT}

In this article, examples and suggestions for the use of reflux techniques in training in the study of foreign language science taught in medical universities are presented, along with ideas on how to not be afraid of learning a foreign language that will help medical students to become more mature and comprehensively educated in the future and what is important in the introduction This opens up a wide range of opportunities for discussion with the staff of the world's leading medical institutions about the symptoms of patients, their treatment methods, books published in foreign languages..

\section{KEYWORDS}

Reflexia, non-traditional methods, training, motivation.

\section{INTRODUCTION}

Currently, one of the goals of socio-economic development is a radical reform of the education system, that is, the processes of improving the quality of education, renewing education and, as a consequence, changing the system of professional development. Only 
specialists with the potential for creativity in the new conditions of the era, distinguished by non-traditional methods of pedagogical thinking, capable of competently solving problems arising in their professional activities, will be able to change pedagogical realities and achieve effective results[2, p. 5].

In teaching foreign languages to students of higher educational institutions, reflexive techniques, which are one of the pedagogical techniques, occupy a special place, since they help the student to reduce the level of fear and anxiety before learning a foreign language. Students who are afraid to respond to the training and are worried will try to do it in different ways, even if they do not understand the assignments that are given to teachers during the training, just because they are afraid to be passive among others. Therefore, it is necessary to apply methods that optimize the learning process in order to increase the level of students' self-confidence, the practical implementation of the knowledge and skills they have acquired.

This article will consider the theoretical foundations of the use of reflection and the practical aspects of organizing students' activities in the educational process using reflection in English lessons.

There are two ways that students can enter a state of reflection, these are linguistic ways of pure thinking. Linguistic means are units of vocabulary, syntactic constructions, etc. The second category includes various (scientific, philosophical, aesthetic, etc.) understandings and categories. The sufficient availability of these methods allows not only to go into a reflexive state, but also to represent the reflected situation and implement various methods of understanding.

In foreign language lessons, the teacher should always give the students ways to enter and use the pure thinking space (diagrams, graphs, formulas, maps, etc.).

\section{MATERIAL AND METHODS}

It is necessary to organize the activities of students so that they enter a stronger reflexive state. This can be achieved by interpreting the student's actions in terms of strong categories, forcing him to reflect his actions using these categories as a means, and to perform actions defined by these categories.

When implementing communicative-dialogical speech, it is necessary to begin a free exchange of views, determine the position of each listener through communication, turn to self-knowledge (reflection) with the help of interrogative exercises, irony or jokes, activate thinking and use analogies. It is also important to maintain a positive emotional state during exercise. Use short texts and quotes during the training; What is the content of the text, in your opinion, the title ... "and so on. Such questions lead the reader directly into a reflexive state. Analysis of the text allows you to transfer existing reflexive positions to the most studied students and to model existing reflexive relations.

One of the ways that can serve as an example of the use of a reflective approach when conducting foreign language lessons is the use of interactive exercises equipped with visual aids on the subject, which also gives a positive result. In this case, during the training, it is not provided for the transfer of information to the students, but for the expression of their opinion on this situation.

Another example is using the conversational method. He has a strong reflection, the teacher asks the audience questions, thereby attracting students to the reflective field.

\section{DISCUSSION AND CONCLUSION}

Reflexive thinking in learning should actively use various means of encouragement, which can be cited as examples: group discussions, 
methods of structured conversation, business games. Of course, reflection is part of the practice of teaching foreign languages. It is certainly capable of being creative in the teacher's teaching.

Since reflection is a kind of summing up the results of the educational activities of students, a kind of introspection that allows you to fix the achieved result and evaluate your work.

Reflection is what you took from the lesson, understood and expressed in your own words. It arises at all stages of educational and pedagogical activity, manifesting itself in various forms and types of this activity (thinking, solving educational problems, cooperation and communication, selfawareness).

At what stage of the lesson should reflection be carried out? Teachers and psychologists believe that reflection can be carried out not only at the end of the lesson, as is commonly believed, but also at any stage of it. Reflection is aimed at realizing the path traveled, at collecting into the common piggy bank what is noticed, thought out, understood by everyone. Its goal is not just to leave the lesson with a fixed result, but to build a semantic chain, compare the methods and methods used by others with their own.

When interacting with students, the teacher uses, depending on the circumstances, one of the types of educational reflection, reflecting the four spheres of human essence:

Physical (had time - did not have time);

Sensory (well-being: comfortable uncomfortable);

Intellectual (that he understood, that he realized - that he did not understand, what difficulties he experienced);
Spiritual (became better - worse, created or destroyed oneself, others).

If physical, sensory and intellectual reflection can be both individual and group, then the spiritual should be carried out only in writing, individually and without publicizing the results. Knowing the classification, it is more convenient for the teacher to vary and combine techniques, including reflection in the lesson plan.

Reflections are distinguished by content, by form of activity and by purpose.

I. The content is symbolic, oral and written.

Symbolic - when a student simply gives a grade using symbols (cards, tokens, gestures, etc.).

Oral involves the child's ability to coherently express their thoughts and describe their emotions. Writing is the most difficult and takes the most time. The latter is appropriate at the final stage of studying an entire section of educational material or a large topic.

II. By the form of activity: collective, group, frontal, individual.

It is in this order that it is more convenient to teach children to this type of work. First - with the whole class, then - in separate groups, then - selectively interview students. This will prepare students for self-improvement.

\section{ACKNOWLEDGEMENT}

Based on the above, we can conclude that the use of reflection in teaching foreign languages is a personality trait and is formed along with it, which allows the student to evaluate their actions, thoughts and results, remove the "language barrier" and form language motivation. 


\section{REFERENCES}

1. Aseev V.G. Motivation of behavior and personality formation. M., 2006.304 p.

2. Bizyaeva A.A. Psychology of a Thinking Teacher: Pedagogical Reflection. - Pskov: PSPI named after S.M. Kirov, 2004 - 216 p.

3. Bodrov V.A. Non-linear model of the motivational sphere of the individual. Psychological journal. Volume 22, $90 \mathrm{p}$.

4. Dikan V.S. Reflexive approach in the theory and practice of training future teachers at US universities (pedagogical aspect). Simferopol, $1999.250 \mathrm{p}$.

5. Zagashev I.O., Zair - Bek S.I., Mushtavinskaya I.V. Teaching children to think critically. - SPb publishing house "Rech", 2003

6. Zair-Bek S.I., Mushtavinskaya I.V. Development of critical thinking in the classroom. - M.: Education, 2011.224 p.

7. What should be a modern lesson. http://www.it-n.ru.

8. Solovova E.N. Methodology for teaching foreign languages. Advanced course: a guide for pedagogical universities students and teachers. M: AST Astrel, 200 p. 